\title{
BIOLOGICAL AND PHOTO-FENTON TREATMENT OF OLIVE OIL MILL WASTEWATER
}

\author{
F. FERREIRA ${ }^{1}$ \\ L. CARVALHO \\ R. PEREIRA ${ }^{2}$ \\ S.C. ANTUNES ${ }^{2}$ \\ S.M. MARQUES ${ }^{2}$ \\ F. GONÇALVES ${ }^{2}$ \\ A.C. DUARTE ${ }^{3}$ \\ T.A.P. ROCHA-SANTOS ${ }^{1}$ \\ A.C. FREITAS ${ }^{1, *}$
}

Received: 18/12/07

Accepted: 18/03/08

\author{
${ }^{1}$ ISEIT/Viseu, Instituto Piaget, Estrada do Alto do Gaio \\ Galifonge, 3515-776 Lordosa, Viseu, Portugal \\ ${ }^{2}$ CESAM \& Department of Biology, University of Aveiro \\ 3810-193 Aveiro, Portugal \\ ${ }^{3}$ CESAM \& Department of Chemistry \\ University of Aveiro, 3810-193 Aveiro, Portugal
}

\begin{abstract}
Olive oil wastewaters (OOMW) are dark effluents which pose serious environmental problems. The aim of this work was to apply biological treatment with Pleurotus spp., and chemical treatment, through oxidation by Photo-Fenton, to OOMW. The biological treatment was not very efficient in colour reduction. In $25 \%$ OOMW dilution treated with $P$. sajor caju or $P$. ostreatus, high percentages of colour reduction $(460 \mathrm{~nm})$ were recorded after 6 days $(70.3$ and $54.7 \%$ ) but, thereafter, great oscillations were observed. In terms of $\mathrm{pH}$, a similar profile was recorded in $25-50 \%$ dilutions treated either with $P$. sajor caju or $P$. ostreatus. Both species grew in OOMW and were responsible for COD reduction, which was greater in the OOMW treated with $P$. sajor caju. The Photo-Fenton reaction was very efficient $(>90 \%)$ in colour reduction. The best combination of $\mathrm{H}_{2} \mathrm{O}_{2} / \mathrm{Fe}$ concentrations was found to be $6 \mathrm{ml}$ of $\mathrm{H}_{2} \mathrm{O}_{2}(70 \%)$ plus $1 \mathrm{ml}$ of $\mathrm{FeSO}_{4}(0,5 \mathrm{M})$. In terms of toxicity reduction tested for Daphnia longispina, the biological and chemical treatments also had a different efficiency. Further research will be carried out to assess the combined application of both treatments, and it's effectiveness in the improvement of the main concerning properties of this industrial effluent.
\end{abstract}

KEYWORDS: Olive oil mill wastewater, Photo-Fenton oxidation, biological treatment, Fungi, Pleurotus spp.

\section{INTRODUCTION}

The chemical composition of the olive oil mill wastewater (OOMW) depends on the extraction process. OOMW is an aqueous, dark, foul smelling and turbid liquid, which includes emulsified grease; it is easily fermentable and has a high organic content (Sierra et al., 2001). The three-phase olive oil extraction process generates an effluent which is characterized by a high polluting load, mainly explained by the presence of chemical compounds, phenols in particular, with biostatic and phytotoxic activity (Casa et al., 2003). Treatment and disposal of OOMW represents one of the main problems for olive oil producing countries of the Mediterranean basin. Every year, a large amount of this wastewater is stored in ponds to precipitate solid organic compounds, until further production. The disposal of this effluent is usually made in local rivers or agricultural soils, representing a major environmental problem because of its potential to compromise the quality of groundwater and surface freshwater resources and, soil functions as well. Thus, it poses a serious risk to aquatic and terrestrial biota, and subsequently to the health of corresponding ecosystems. Studies focusing the characterisation and evolution of a soil affected by OOMW disposal showed that, even after two years of sediment removal, residual contamination levels are still considerable, in the 
upper $40 \mathrm{~cm}$ of soil (Sierra et al., 2001). Hence, the great risk of producing irreversible environmental problems justifies the development of appropriate technologies to reduce toxic compounds, especially the phenolic content of this industrial residue. Phenolics present on OOMW at high concentrations (1-10 $\left.\mathrm{g} \mathrm{l}^{-1}\right)$ are considered as the major recalcitrant compounds, which have antimicrobial properties, and are difficult to be biologically degraded (Ahmadi et al., 2005). Besides biological treatments with fungi have been pointed by several authors as the most effective and inexpensive (e.g. Yesilada et al., 1999; Isidori et al., 2004), it is also known that conventional biological processes for the purification of OOMW are sometimes inefficient and must be coupled with other processes. Oxidation processes that utilize $\mathrm{H}_{2} \mathrm{O}_{2}, \mathrm{O}_{3}$ or $\mathrm{O}_{2}$ as oxidants, are very promising techniques for remediation of wastewaters having non-biodegradable organic pollutants (Scott and Ollis, 1995, Gogate and Pandit, 2004). These processes involve the generation of the hydroxyl radical that is a reactive intermediate and has a high oxidation potential (Sarria et al., 2002).

Based on these assumptions, the aim of this work was to apply a biological treatment to OOMW, stored in a pond for about one year, with Pleurotus spp., as well as a Photo-Fenton's oxidation, which is considered as an iron-catalyzed $\mathrm{H}_{2} \mathrm{O}_{2}$ decomposition reaction. Between the different fungi used in OOMW treatment, Pleurotus presents the advantage of being an edible mushroom.

\section{MATERIAL AND METHODS}

\subsection{Source of inoculum and maintenance}

Two species of Pleurotus: $P$. sajor caju and $P$. ostreatus were obtained from Faculdade de Ciências Agrárias - UNESP, São Paulo Brasil and subcultured and maintained on Potato Dextrose Agar (Himédia $\AA^{\circ}$, India), at $4^{\circ} \mathrm{C}$. Growth of Pleurotus mycelia was performed in sterilized media containing $2 \mathrm{~g} \mathrm{l}^{-1}$ glucose (Riedel-Haen ${ }^{\circledR}$, Germany), $2 \mathrm{~g} \mathrm{l}^{-1}$ starch (Absolve $\AA$, Portugal), $0.1 \mathrm{~g} \mathrm{l}^{-1}$ peptone (Hi-media ${ }^{\circledR}$, India), during 7 days, at $25^{\circ} \mathrm{C}$ and, $120 \pm 10 \mathrm{rpm}$. After growth, mycelia was collected by filtration with sterilized gaze and kept in sterilized plastic containers at $4^{\circ} \mathrm{C}$, for a maximum of $24 \mathrm{~h}$, until the biological treatment of the OOMW started.

\subsection{Effluent source}

Olive oil mill wastewater with about one year, from settlement ponds of a company that receives wastes from local oil presses (S. João da Pesqueira, North of Portugal) was collected and stored in glass flask, in the dark, at $4^{\circ} \mathrm{C}$ until biological and Photo-Fenton treatment.

\subsection{Biological treatment of $O O M W$ in batch reactor}

In order to determine the maximum OMWW concentration, at which fungal growth of Pleurotus spp. was not inhibited and, if autochthonous microorganisms can promote decolourisation as well, cultures on solid media were conducted in duplicate, in plates containing sterile and non-sterile solutions. These solutions were composed by OOMW in different concentrations (25, 50 and $75 \%$ ), chemical additives and 16\% (w/v) agar (Himedia, India). Two different mixtures of chemical additives were used, namely: (i) $20 \mathrm{~g} \mathrm{I}^{-1}$ of glucose, $20 \mathrm{~g} \mathrm{I}^{-1}$ of starch and $1 \mathrm{~g} \mathrm{I}^{-1}$ peptone or (ii) $1 \mathrm{~g} \mathrm{l}^{-1} \mathrm{KH}_{2} \mathrm{PO}_{4}$ (Sigma, USA), $0.25 \mathrm{~g} \mathrm{l}^{-1} \mathrm{NH}_{4} \mathrm{Cl}$ (Sigma, USA) and $0.05 \mathrm{~g} \mathrm{I}^{-1}$ yeast extract (Hi-media, India).

To perform the biological treatment, liquid cultures of two different concentrations of the original OOMW (25 and 50\%) were obtained through dilution with water. Thereafter, several compounds were added to the diluted OOMW according to Jaouani et al. (2003) suggestions: $\mathrm{KH}_{2} \mathrm{PO}_{4}\left(1 \mathrm{~g} \mathrm{l}^{-1}\right), \mathrm{NH}_{4} \mathrm{Cl}\left(0.25 \mathrm{~g} \mathrm{l}^{-1}\right)$ and yeast extract $\left(0.05 \mathrm{~g} \mathrm{l}^{-1}\right)$. Two replicas of $190 \mathrm{ml}$ of each dilution were inoculated with 5-6 g of Pleurotus ostreatus or $P$. sajor-caju mycelia. The $\mathrm{pH}$ of both dilutions was adjusted to 5.4-5.5 and incubation was performed at $25^{\circ} \mathrm{C}$ and $120 \pm 10 \mathrm{rpm}$, for 27 days.

Several parameters were analysed to monitor the biological treatment of OOMW with Pleurotus spp. Samples were withdrawn after 0, 6, 12, 20, and 27 days of incubation for $\mathrm{pH}$ and colour control. Colour removal was followed by UV-VIS scan $(200-600 \mathrm{~nm})$ of diluted samples at $\mathrm{pH}$ 5.5. Chemical oxygen demand (COD) was analyzed according to ASTM method (1994) after 0 and 27 days of incubation. Mycelia of both species of Pleurotus was harvested by filtration and weighed after 27 days of treatment for biomass control. 


\subsection{Photo-Fenton treatment}

The Photo-Fenton treatment was performed with aliquots of $50 \mathrm{ml}$ of OOMW, with $\mathrm{pH}$ adjusted to 4.2 , in a $100 \mathrm{ml}$ glass reactor maintained at $20^{\circ} \mathrm{C}$. The aqueous solution of reactants was homogenised by magnetic stirring to avoid concentration gradients. The influence of different concentrations of $\mathrm{H}_{2} \mathrm{O}_{2}$ as well of iron was studied. Hence, to assess the influence of different $\mathrm{H}_{2} \mathrm{O}_{2}$ concentrations, $3 \mathrm{~mL}$ of $\mathrm{FeSO}_{4}(0.5 \mathrm{M})$ and different volumes of $\mathrm{H}_{2} \mathrm{O}_{2}(70 \%), 3,6,9,12$ and $15 \mathrm{ml}$ were added to $50 \mathrm{ml}$ of OOMW, in batch assays. Each volume of $\mathrm{H}_{2} \mathrm{O}_{2}$ was divided in equal aliquots, to be added each 10 minutes, within the period of 1 hour. The same procedure was followed to study the influence of iron concentrations i.e. after the addition of $6 \mathrm{~mL}$ of $\mathrm{H}_{2} \mathrm{O}_{2}$ to the OOMW, different volumes of $\mathrm{FeSO}_{4} 0.5 \mathrm{M}(0.05,0.2$, 1,2 and $3 \mathrm{ml}$ ) were added. The UV light was switch on, after addition of the first aliquot and left for 2 hours. After 6 days, aliquots of treated effluent were collected, filtered through a glass fibber and submitted to UV/Vis analysis to quantify colour reduction.

\subsection{Acute toxicity assays}

Monoclonal cultures of D. longispina (clone EM7, sensu Antunes et al. 2003) were reared under a $16^{\mathrm{L}}: 8^{\mathrm{D}} \mathrm{h}$ cycle and a temperature of $20 \pm 2^{\circ} \mathrm{C}$. ASTM (1980) synthetic hard water medium was used as culture medium and rearing procedures followed the recommendations of standard protocols (e.g. ISO, 1996 and 2000; ASTM, 1997; OECD, 1998 and 2000). A standard organic additive was added to the culture to provide essential microelements to daphnids (Baird et al., 1989). Animals were fed with Pseudokirchneriella subcapitata, which was cultured in Woods Hole MBL medium, in a semi continuous $8 \mathrm{~L}$ batch culture at a $24^{\mathrm{L}}: 0^{\mathrm{D}} \mathrm{h}$ regime (at $20 \pm 2{ }^{\circ} \mathrm{C}$ ). Algal ration was determined spectrophotometrically and daily supplied to the cladocerans $\left(1.5 \times 10^{5} \mathrm{cell} / \mathrm{ml} /\right.$ day for $D$. longispina $)$.

Sub-samples of OOMW, after have been treated by fungi or by Photo-Fenton reaction, and with $\mathrm{pH}$ adjusted to 7.5 , were taken for acute toxicity evaluation with $D$. longispina. All assays were initiated with neonates $\left(<24\right.$-h-old), born between the $3^{\text {rd }}$ and $5^{\text {th }}$ broods, which were obtained from bulk group cultures. Assays were performed in accordance with standard protocols (ISO, 1996; ASTM, 1997; OECD, 2000), under the same temperature and photoperiod regimes as described for rearing procedures. A static design was employed, using 20 animals (randomly divided into four groups of five animals) per control and per OOMW concentration (\%). Test vessels (four per each concentration) consisted of glass beakers containing $100 \mathrm{ml}$ of each effluent concentration. All experimental treatments were checked for immobilised individuals at 24 and 48h, which were counted for posterior determination of $\mathrm{EC}_{50}$ values. $\mathrm{EC}_{50}$ values for immobilisation data were determined using probit analysis (Finney, 1971).

\section{RESULTS}

Both species of Pleurotus spp. only were able to growth in 25\% OOMW (sterilized and nonsterilized) solid cultures, where some decolourisation of the medium progressively occurred compared to the corresponding control (non-inoculated plates). In plates with 50 and $75 \%$ dilutions of OOMW, no growth was observed. In plates with the non-sterilized $25 \%$ dilution of OOMW and without the inoculation of fungi species, the growth of autochthonous microorganisms was recorded, but no decolourisation occurred, which indicates the inability of the OOMW autochthonous microflora to degrade complex organic compounds.

In liquid cultures, both species grew in the 25 and 50\% OOMW dilutions, especially $P$. ostreatus whose growth rate was higher (1.6) in the $25 \%$ OOMW dilution (Table 1). According to Tsioulpas et al. (2002), OOMW contains all essential elements for microbial growth, but also several growth inhibitors, such as organic acids and phenolic compounds whose composition depends on maturity and variety of olive fruit and mainly on the oil extraction technology used.

OOMW is usually characterized by a high degree of organic pollution presenting values of COD up to $220 \mathrm{~g} \mathrm{I}^{-1}$ (Tsagaraki et al., 2007). In our study, levels of COD reduction were greater in the OOMW inoculated with $P$. sajor caju. A 50 and $89 \%$ reduction in COD was attained in the $50 \%$ and $25 \%$ OOMW dilutions, respectively, after 27 days of incubation with $P$. sajor caju. P. ostreatus seemed to have more difficulties in promoting degradation of organic compounds responsible for COD levels in this type of effluent. As Jaouani et al. 
(2003) observed, COD removal is correlated with high levels of decolourisation, especially for species such as $C$. polyzona and $P$. sajor caju.

Table 1. Biomass and COD values obtained in treated OOMW with $P$. sajor caju or $P$. ostreatus, throughout 27 days of incubation at $25^{\circ} \mathrm{C}$ and $120 \pm 10 \mathrm{rpm}$

\begin{tabular}{|c|c|c|c|c|c|c|}
\hline \multirow{2}{*}{$\begin{array}{c}\text { Effluent } \\
\text { composition }\end{array}$} & \multirow{2}{*}{ Fungi } & \multicolumn{3}{|c|}{ Biomass $\left(\mathrm{gl}^{-1}\right)$} & \multicolumn{2}{|c|}{$\operatorname{COD}\left(\mathrm{g} \mathrm{I}^{-1}\right)$} \\
\hline & & $0 \mathrm{~d}$ & $27 d$ & $\mathrm{GR}^{1}$ & $0 \mathrm{~d}$ & $14 \mathrm{~d}$ \\
\hline $25 \%$ & P. sajor caju & 5.02 & 6.22 & 1.2 & 6.47 & 0.71 \\
\hline $25 \%$ & P. ostreatus & 5.32 & 8.34 & 1.6 & 6.47 & 4.41 \\
\hline $50 \%$ & P. sajor caju & 5.41 & 6.20 & 1.1 & 12.03 & 6.01 \\
\hline
\end{tabular}

The biological treatment, in liquid cultures, was not very efficient in terms of colour reduction, since throughout incubation time high oscillations in absorbance, at 250, 275, 325, 400 and $460 \mathrm{~nm}$, were recorded (Table 2).

Table 2. Absorbance reduction ( $\%)^{1}$ for several wave lengths in treated 25 and $50 \%$ OOMW dilutions treated with $P$. sajor caju or $P$. ostreatus, throughout 27 days of incubation at $25^{\circ} \mathrm{C}$ and $120 \pm 10 \mathrm{rpm}$.

\begin{tabular}{|c|c|c|c|c|c|c|}
\hline \multirow{2}{*}{$\begin{array}{c}\text { Effluent } \\
\text { composition }\end{array}$} & \multirow{2}{*}{ Fungi } & \multirow{2}{*}{$\underset{(\mathrm{nm})}{\lambda}$} & \multicolumn{4}{|c|}{ Time (d) } \\
\hline & & & 6 & 12 & 20 & 27 \\
\hline \multirow{11}{*}{$25 \%$} & \multirow{5}{*}{ P. sajor caju } & 250 & 31.5 & 5.7 & 16.0 & 23.4 \\
\hline & & 275 & 39.1 & 3.7 & 13.7 & 18.4 \\
\hline & & 325 & 33.2 & 2 & 2 & \\
\hline & & 400 & 49.8 & -2 & 21.4 & 23.2 \\
\hline & & 460 & 70.3 & -2 & 42.6 & 44.7 \\
\hline & \multirow{6}{*}{ P. ostreatus } & & & & & \\
\hline & & 250 & 10.0 & 2.0 & 1.5 & 2.5 \\
\hline & & 275 & 14.8 & 4.2 & $-^{2}$ & $2^{2}$ \\
\hline & & 325 & 5.9 & 2 & -2 & -2 \\
\hline & & 400 & 28.0 & 5.5 & -2 & $-^{2}$ \\
\hline & & 460 & 54.7 & 32.5 & 23.8 & 18.4 \\
\hline \multirow{5}{*}{$50 \%$} & \multirow{5}{*}{ P. sajor caju } & 250 & -2 & -2 & 24.6 & -2 \\
\hline & & 275 & 16.1 & 21.5 & 36.2 & 10.9 \\
\hline & & 325 & -2 & -2 & 2.6 & $-^{2}$ \\
\hline & & 400 & $-^{2}$ & 2.3 & 21.5 & -2 \\
\hline & & 460 & 10.5 & 30.2 & 40.7 & 17.5 \\
\hline
\end{tabular}

${ }^{1} \mathrm{Absorbance}$ reduction percentage $=($ Final Abs - Initial Abs $) /$ Initial Abs $) \times 100 ;$ ${ }^{2}$ No absorbance reduction.

In the 25\% OOMW dilution, treated with $P$. sajor caju and $P$. ostreatus, interesting percentages of colour reduction were recorded after 6 days of incubation at $460 \mathrm{~nm}$ (70.3 and $54.7 \%$, for each species, respectively). Thereafter, great oscillations were observed and the percentages of colour reduction, at $460 \mathrm{~nm}$, after 27 days of incubation, decreased for 44.7 and $18.4 \%$ in effluent incubated with $P$. sajor caju and $P$. ostreatus, respectively. The lowest values of colour reduction were observed in the 50\% OOMW dilution. Jaouani et al. (2003) reported a transient colour increase phase during the first days of incubation of OOMW with fungi before effective decolourisation started. Other authors have reported a progressive decolourisation by Pleurotus spp. throughout incubation time (Tsioulpas et al., 2002; Fountoulakis et al., 2002). However, the colour variation observed could somewhat have been related with the inhibition of the fungal enzyme laccase, since in Pleurotus ostreatus this is the enzyme responsible for the oxidation of phenolic compounds and aromatic amines and 
it is usually induced by OMWW or other substrates (Martinari et al., 1986; Hublick and Schinner, 2000).

According to Piperidou et al. (2000), the OMWW contains some phenolic compounds, which are able to induce laccase synthesis. However, as reported by Tsajaraki et al. (2007), the majority of phenolic compounds removed are simple monomers, whereas polymerized molecules such as tannins are more resistant to degradation because these compounds absorb strongly to mycelia and intracellular enzymes, causing inactivation, imparing their own biodegradation. In fact, more than 30 different phenolic compounds have been detected which can be included in two categories: (i) phenolic monomers, flavenoids, not autoxidated tannins, and other compounds with MW $\leq 10 \mathrm{KDA}$ and (ii) medium and high molecular weight (MW) dark coloured polymers resulting from the polymerization and autoxidation of phenolic compounds (Tsajaraki et al., 2007).

In terms of $\mathrm{pH}$, a similar profile was recorded in the 25 and 50\% OMWW dilutions, inoculated either with $P$. sajor caju or $P$. ostreatus (Figure1), throughout 27 days of incubation, at $25{ }^{\circ} \mathrm{C}$ and $120 \pm 10 \mathrm{rpm}$. In all the assays the highest values were recorded after 6 days of incubation (7.1-7.7), decreasing afterwards until values around 4 after 27 days of treatment. The highest values of $\mathrm{pH}$ are in agreement with higher values of absorbance reduction in $25 \%$ OMWW dilution, recorded after 6 days of incubation.

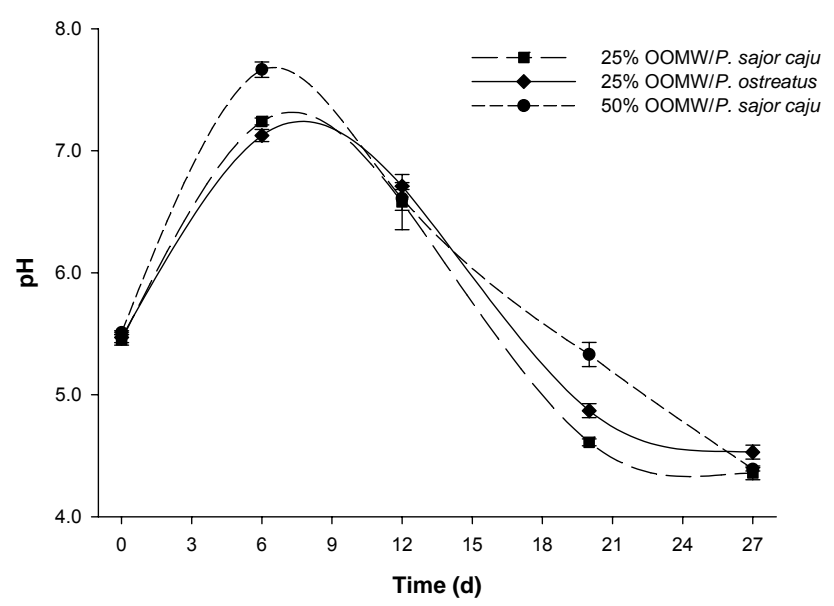

Figure 1. $\mathrm{pH}$ variation throughout time of $25 \%$ to $50 \%$ OOMW dilutions inoculated with $P$. sajor caju or $P$. ostreatus at $25^{\circ} \mathrm{C}$ and $120 \pm 10 \mathrm{rpm}$

The Photo-Fenton reaction revealed to be very efficient in terms of colour removal. Levels above $90 \%$ in colour reduction were found in several combinations of $\mathrm{H}_{2} \mathrm{O}_{2}$ /iron concentrations. The best combination of $\mathrm{H}_{2} \mathrm{O}_{2}$ /iron concentrations was found to be $6 \mathrm{ml}$ of $\mathrm{H}_{2} \mathrm{O}_{2}(70 \%)$ plus $1 \mathrm{ml}$ of $\mathrm{FeSO}_{4}(0,5 \mathrm{M})$. With this combination 85.7, 91.9 and $93.4 \%$ of color reduction were obtained at 400,460 and $500 \mathrm{~nm}$, respectively (Figure 2). The $\mathrm{Fe}^{2+} / \mathrm{H}_{2} \mathrm{O}_{2}$ system is efficient to treat OMWW due to $\mathrm{OH}$ radical peroxidation and ferrous /ferric coagulation (Khoufi et al., 2006). The non-biodegradable organics and toxic pollutants present in the wastewater such as polyphenols are usually destroyed by oxidation via production of oxidants such as hydroxyl radicals and complex coagulants that promote the flocculation of the matter present in the OOMW (Panizza et al., 2000; Chen et al., 2002).

A high OOMW effluent acute toxicity was observed for $D$. longispina [(with $\mathrm{pH}$ adjusted to 7.5 ) $\left.-\mathrm{EC}_{50}=6.02 \%\left(\mathrm{Cl}_{95}: 5.48 \%-6.37 \%\right)\right]$. P. sajor caju was more efficient in the reduction of toxicity of the OOMW to Daphnia longispina. The 48h-EC50 increased 4.6 and 3.3 folds after the treatment with $P$. sajor caju and $P$. ostreatus, respectively. Regarding the effluent treated with Photo-Fenton reaction any improvement was recorded in its toxic properties. Although, it was not possible to determine an $\mathrm{EC}_{50}$, immobilization was observed for daphnids in all the concentrations equal or above $7 \%$. Further research will follow in order to study the combination of both, chemical oxidation and biological treatment, applied to larger volumes of OOMW, in increasing the removal of toxic compounds as products from a partial chemical degradation are more easily biodegradable. 

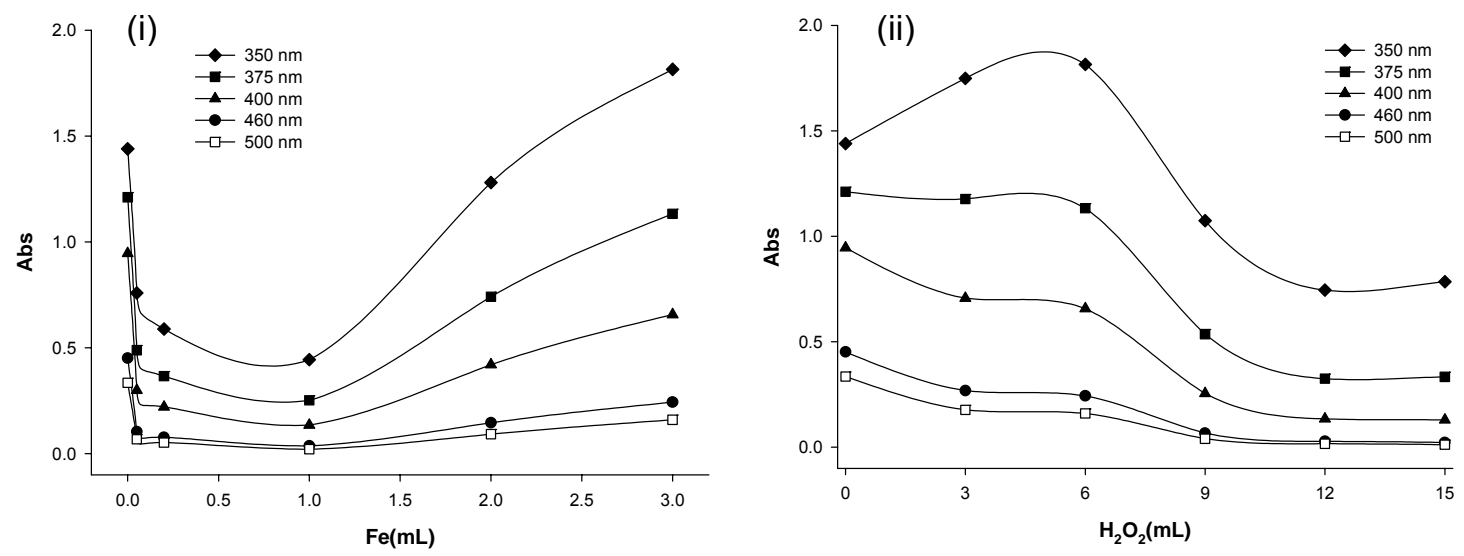

Figure 2. Absorbance values obtained from Photo-Fenton treatment of OOMW with

(i) $6 \mathrm{ml}$ of $\mathrm{H}_{2} \mathrm{O}_{2}$ varying the volume of $\mathrm{Fe}(0.05 \mathrm{M})$ and

(ii) $3 \mathrm{ml}$ of $\mathrm{Fe}(0.05 \mathrm{M})$ varying the volume of $\mathrm{H}_{2} \mathrm{O}_{2}(37 \%)$

\section{CONCLUSIONS}

Pleurotus spp. species appear to be able to grow on OMWW with levels of $25 \mathrm{~g} \mathrm{l}^{-1}$ of COD. However, and in contrast to results reported by several authors, the decolourisation of the effluent was not progressive. High oscillations of absorbance at several wave lengths was recorded which could be related with polymerisation and other reactions of several compounds namely phenolic monomers. In further research enzymatic activity, phenolic compounds and other organic molecules will be measured in order to follow the biological treatment of OMWW.

\section{REFERENCES}

Ahmadi M., Vahabzadeh F., Bonakdarpour B., Mofarrah E. and Mehranian M., (2005) Application of the central composite design and response surface methodology to the advanced treatment of olive oil processing wastewater using Fenton's peroxidation, J. Harzardous Materials, B123, 187-195.

Antunes S.C., Castro B.B., Gonçalves F., (2003) Chronic responses of different clones of Daphnia longispina (field and ephippia) to different food levels, Acta Oecol, 24, S325-S332.

ASTM (1980) Standard practice for conducting acute toxicity tests with fishes, macroinvertebrates and amphibians, Annual Book of ASTM Standards, Report E 729-80, American Society for Testing and Materials, Philadelphia, USA.

ASTM (1980) Standard practice for conducting acute toxicity tests with fishes, macroinvertebrates and amphibians, Annual Book of ASTM Standards, Report E 729-80, American Society for Testing and Materials, Philadelphia, USA.

ASTM (1994) Standard Test Methods for Chemical Oxygen Demand of Water, Annual Book of ASTM Standards, Report D 1252-88, American Society for Testing and Material, Philadelphia, USA.

ASTM (1997) Standard guide for Daphnia magna life-cycle toxicity tests, Annual Book of ASTM Standards, Report E1193-97, American Society for Testing and Materials, Philadelphia, USA.

Baird D.J., Soares A.M.V.M., Girling A., Barber I., Bradley M.C., Calow P., (1989) The long-term maintenance of Daphnia magna Straus for use in ecotoxicity tests: problems and prospects, In: Proceedings of the First European Conference on Ecotoxicology, Lokke, H., Tyle, H., BroRasmussen, F. (Eds.), Lyngby, Denmark, 144-148.

Casa R., D'Annibale A., Pieruccetti Stazi S.R., Giovannozzi S.G. and Locascio B., (2003) Reduction of the phenolic components in olive-mill waste-water and its impact on durum wheat germinability, Chemosph., 50, 959-966.

Chen X., Chen G. and Yue P.L. (2002) Novel electrode sustem for electroflotation of wastewater, Environ. Sci. Technol., 26, 778-783.

Finney D.J., (1971) Probit Analysis, Cambridge University Press, Cambridge, UK 
Fountoulakis M.S., Dokianakis S.N., Kornaros M.E., Aggelis G.G. and Lyberatos G. (2002) Removal of phenolics in olive mill wastewaters using the white-rot fungus Pleurotus ostreatus, Water Res., 36, 4735-4744.

Gogate P.and Pandit A. (2004) Review of imperative technologies for wastewater treatment. Partl: oxidation technologies at ambient conditions, Adv. Environment Research, 8, 504-551.

Hublik G. and Schinner G. (2000), Characterization and immobilization o the laccase from Pleurotus ostreatus and its use for the continuous elimination of phenolic pollutants, Enz. Microb. Technol., 27, 330-336.

Isidori M., Lavorgna M., Nardelli A. and Parrella A., (2004) Chemical and toxic evaluation of biological treatment for olive-oil mill wastewater using commercial microbial formulations, App. Microbiol. Biotechnol., 64, 735-739.

ISO (1996) Water quality: determination of the inhibition of the mobility of Daphnia magna Straus (Cladocera, Crustacea) - Acute toxicity test, ISO International Standard 6341. International Organization for Standardization, Geneva, Switzerland.

Jaouani A., Sayadi S., Vanthournhout M. and Penninckx M.J., (2003). Potent fungi for decolourisation of olive oil mill wastewaters, Enz. Microbio. Technol., 33, 802-809.

Scott J. and Ollis D., (1995) Integration of chemical and biological oxidation process for water treatment: review and recommendations, Environment Progr., 14, 88-103.

Martirani L., Giardina P., Marzullo L. And Sannia G., (1996) Reduction of phenol content and toxicity in olive oil mill waste waters with the ligninolytic fungus Pleurotus ostreatus, Water Res., 30, 1914-1918.

OECD (2000) Daphnia sp., acute immobilisation test, Revised proposal for updating guideline 202. Organization for the Economic Cooperation and Development, Paris, France.

Piperidou C., Cahidou C., Stalikas C., Soulti K. Pilidis G. and Balis C., (2000) Bioremediation of olive oil mill wastewater: chemical alterations induced by Azotobacter vinelandi', J. Agr. Food Chem., 48, 1941-1948.

Sarria V., Parra S., Adler N., Peringer P., Benitez N. and Pulgarin C., (2002) Recent developments in the coupling of photoassisted and aerobic biological processes for the treatment of biorecalcitrant compounds, Catal. Today, 76, 301-315.

Sierra J., Marti E., Montserrat G., Cruañas R.and Garau M.A., (2001) Characterisation and evolution of a soil affected by olive oil mill wastewater disposal, Sci. Total Environ., 279, 207214.

Tsagaraki E., Lazarides N. and Petrotos K.B., (2007) Olive mill wastewater treatment, In: Utilization of by-products and treatment of waste in the food industry, Oreopoulou, $\mathrm{V}$ and Russ, W. (Ed.), Springer Science+Business Media, LLC, NY, USA.

Tsioulpas, A., Dimou, D., Iconomou, D. and Aggelis, G. (2002) Phenolic removal in olive oil mill wastewater by strains of Pleurotus spp. in respect to their phenol oxidase (laccase) activity, Biores. Technol., 84, 251-257.

Yesilada O., Sik S. and Sam M., (1999) Treatment of olive oil mill wastewater with fungi, Tr. J. of Biology, 23, 231-240. 